\title{
EXCESS VERSIONS OF THE MINKOWSKI AND HÖLDER INEQUALITIES
}

\section{IOSIF PINELIS}

Abstract. Certain excess versions of the Minkowski and Hölder inequalities are given.

Mathematics subject classification (2010): 26D15, 60E15.

Keywords and phrases: Minkowski's inequality, Hölder's inequality, $p$-excess.

\section{REFERENCES}

[1] S. KARLin AND W. J. STUdDEn, Tchebycheff systems: With applications in analysis and statistics, Pure and Applied Mathematics, vol. XV. Interscience Publishers John Wiley \& Sons, New YorkLondon-Sydney, 1966.

[2] J. H. B. KemPERMAN, On the FKG-inequality for measures on a partially ordered space, Nederl. Akad. Wetensch. Proc. Ser. A 80 = Indag. Math. 39, 4 (1977), 313-331.

[3] MathOverflow, A Minkowski-like inequality, https://mathoverflow.net/q/292327 (version: 2018-02-07).

[4] I. PINELIS, Tchebycheff systems and extremal problems for generalized moments: a brief survey, http://arxiv.org/abs/1107.3493, 2011.

[5] I. PINELIS, On the extreme points of moments sets, Math. Methods Oper. Res. 83, 3 (2016), 325-349.

[6] B. H. Pourciau, Modern multiplier rules, Amer. Math. Monthly 87, 6 (1980), 433-452.

[7] H. L. Royden, Real analysis, Second edition, 1968.

[8] G. WinKLER, Extreme points of moment sets, Math. Oper. Res. 13, 4 (1988), 581-587. 